\title{
Languages of hunter-gatherers through a historical-typological lens
}

Güldemann, Tom \& McConvell, Patrick \& Rhodes, Richard A. (eds.). 2020. The language of hunter-gatherers. Cambridge: Cambridge University Press. xxii +720 pp.

\section{Introduction}

This is a review of the collective volume The language of huntergatherers, edited by Tom Güldemann, Patrick McConvell, and Richard A. Rhodes, featuring 23 chapters, organized into 7 parts ("Introduction", "Africa", “Tropical Asia", "New Guinea and Australia", "Northeastern Eurasia", "North America", "South America"), an appendix "Preliminary worldwide survey of forager languages", a language index, and a subject index. Already from this table of contents, one can immediately see the main aim of the collection: to provide a worldwide survey of hunter-gatherer societies through the lens of their languages. The enterprise is not solely descriptive but rather serves to answer the main research question, whether languages of hunter-gatherers are in any sense different from languages of foodproducers. No modern linguist seriously expects the specifics to lie at the synchronous level of linguistic structures (though see Bickel \& Nichols' chapter discussed below), but the social and sociolinguistic histories of foraging communities might have particular properties when compared to those of foodproducing ones, and these properties might shape their languages. Thus, the main analytic focus of the volume is on the spread and diversification of hunter-gatherer languages, on variation and contact processes observed for them, as well as on linguistic encoding of cultural knowledge specific to hunter-gatherers (note that the terms "huntergatherers" and "foragers" are used interchangeably in the volume and hence in this review).

\section{Overview of the volume as a whole}

The volume originated in the workshop "Historical linguistics and hunter-gatherer populations in a global perspective" held at the Max Planck Institute for Evolutionary Anthropology in Leipzig (Germany), and the emphasis on historical linguistics has shaped its main research question and has remained 
central for most of the individual papers. Many of the papers address the dynamics of forager languages, using the reconstructed evolution of languages of an area to inform the history of subsistence, migrations, and population contact in that area (e.g. the papers by Güldemann, Blevins, Rischel, Burenhult, Reid, Harvey, and Epps). In yet other papers, the argument goes in the opposite direction: externally observed factors like the difference in subsistence of a given linguistic group from its neighbors or known population movements serve as tools which could help to understand the areal linguistic history (e.g. the contributions by Savà \& Tosco, Ross, and Vidal \& Braunstein). In doing so, these studies rely on an assumption that both the peculiarities of subsistence and the peculiarities of a language normally change slowly and gradually, so that atypical abrupt shifts would leave traces that can be detected and analyzed. One paper (Hill) is also devoted to verification and refinement of a particular theory of hunter-gatherer language spreads postulated earlier by one of the editors of the volume (McConvell).

At the same time, there are also papers with a purely synchronic focus interested in possible linguistic contrasts between languages of foragers and those of food producers.
Bickel \& Nichols report on a wide typological survey on the topic. Brown examines a possible difference in botanic terms between foragers and food producers with a case study of oak terms in languages of the USA, but with broader conclusions in mind. Donohue checks for recurrent differences between languages of foragers and those of their food-producing neighbor(s) with three case studies from New Guinea. Harrison \& Anderson are concerned with how the forager lifestyle might be reflected in the peculiarities of two closely related Turkic languages of South Siberia (Tofa and Todzhu). De Reuse refutes the hypothesis of hunter-gatherer primitivism based specifically on the much discussed Eskimo terms for 'snow', where the (wrongly) presupposed absence of a general term has been taken as evidence of weak logical ability.

Some papers of the volume report fully original studies performed specifically for the volume (e.g. those by Bickel \& Nichols, Rischel, Donohue, Sutton, Anderson \& Harrison, de Reuse, Hill, and Epps), even though some of them include previous findings of the authors, published or unpublished. Some are mainly summaries of the authors' expertise in an area, compiled specifically for the volume (e.g. the papers by Rhodes, 
Ross, Burenhult, Soriente, Harvey, McConvell, and Vidal \& Braunstein). Note however that in many cases, the border between these categories is quite fuzzy. Finally, some papers are not original altogether (e.g. Brown) or reproduce linguistic studies published elsewhere, but now with an added (extended) anthropological or ethnographic discussion (e.g. Sava \& Tosco, Guldemann, and Reid).

In most papers, the focus on subsistence is omnipresent, though in some others the reference to subsistence serves merely as a background, often of only minor importance, for a purely linguistic study (e.g. the contributions by de Reuse, and in particular by Vajda and by Rhodes). These papers might be excellent linguistic work, but they do not really contribute to the central discussion of the volume, that of the possible relationship between languages and subsistence types of a given area or typologically.

The editors of the volume have evidently not strived to ensure a particular unity for the collection. There are very few cross-references between papers (even where they would seem the most natural, cf. Sutton's brief reference to a particular language spread in Australia described in detail by Harvey in the chapter immediately following Sutton's) and most areal or typological overviews undertaken in the volume's papers do not mention cases described elsewhere in the book (e.g. see the papers by Gunnarsdóttir \& Stoneking, Rischel, Epps, etc.). In a sense, readers thus have an opportunity to get a retrospective view of the field, that is, what the state of linguistic knowledge on hunter-gatherer languages was up to the time when these papers were written.

While the hunter-gatherers of the Americas, Africa, Australia, and Oceania are regularly mentioned in typologically oriented linguistic literature in English, this is usually not the case for Asia. So, each paper of the section "South Asia", aside from treating its own topics of interest, serves also as a very welcome introduction to the minority languages of the area. Unfortunately, this cannot be said about the section "Northeast Asia"; it contains only two papers, none of which gives an overview of the area comparable to the South Asian overviews. In particular, the Uralic language family is not represented in the volume at all. Even though Anderson \& Harrison note in their chapter, "Siberian reindeer herding peoples (e.g. Khanty, Evenki) are included both in the expanded foregoing definition [from Panter-Brick et al. (2001: 2)] and in the Cambridge encyclopedia of hunters and 
gatherers (Lee and Daly 1999)", the editors of the volume might have had a different opinion. Indeed, in the extensive appendix "Preliminary worldwide survey of forager languages", compiled by all of the authors, only such Uralic languages as Khanty, Mansi, Nganasan, and Selkup are stated to definitely belong to forager languages, with Forest Nenets (and e.g. Evenki and Even) being classified as "uncertain cases", and Forest Enets and Tundra Enets absent altogether. To the best of my knowledge, the Forest Nenets are no more pastoralists than the Nganasans, and the Tundra Enets, and in particular the Forest Enets, are also as clear cases of foragers as the Nganasans are.

The volume took fifteen years to mature, with a workshop back in 2006 setting the first presentation of most of its papers. On the whole, many papers were updated at least a couple of years before publication, though some show signs of outdatedness. Note for example the multiple references to an obsolete ProtoAustronesian reconstruction from 1972 in Reid's paper (p. 232), updated only in a footnote, or Gunnarsdóttir \& Stoneking's paper on the population genetics of huntergatherers, explicitly saying that it was last updated in 2009, which means that today it has a merely historical value (e.g. it mentions methods based on autosomal DNA analysis only in passing and ignores the recent groundbreaking continent-wide studies using these methods).

The quality of the technical editing is good, even though greater perfection could have been expected from such a major academic publisher. There are occasional misprints and missing or inadequate references, maps, or tables, albeit they are not too numerous. For example, Rischel refers to a paper as "the PLoS paper" without any further details (p. 153); Tables 11.5-11.6 referred to in the text are missing (p. 292); Map 12.6 supposed to show languages of North-Western Melanesia is missing (p. 319), as well as Table 12.5 (p. 321); Map 13.1 does not show the areas which the text describes it as showing (p. 337); Table 13.4 does not use italics, though its meaning is explained in the text (p. 344); lists of abbreviations are missing from the papers by Harvey and McConvell; a part of footnotes in McConvell's paper are faulty, with 6 in the text referring to 7 in the list of footnotes, and so on up to 10 in the text, with 11 in the text absent from the list of references, and 6 in the list of references missing in the text; some glosses of examples 17.1, 17.2 (p. 477) and 17.8 (p. 484) are mixed up, as are translations for 'son' and 'God' in the article text and in the glosses 
of example 17.14 (p. 486). I will not bother readers with a list of misprints, but they amount to no more than a couple of dozen for the $700+$ pages of the volume.

\section{Overview of the individual papers}

The rest of this review is devoted to a concise critical description of the individual papers, completed by a brief conclusion on the relevance of the volume to the field of Uralic linguistics. The papers are presented mainly in the order of their appearance in the volume, though I have taken the liberty to group some of them together, which makes an occasional change to the default order.

The book opens with an extended introductory paper by the editors, where they first summarize the anthropological starting point of the debate, the "otherness" of foragers that is expected, at least by anthropologists, to be somehow reflected in their languages. The editors, and actually many authors of individual papers, openly confront the view expressed in Bellwood (2013) (and his earlier works) that puts agricultural language spreads at the forefront and marginalize foragers as participants in the world's linguistic history. After the useful overview of anthropological conceptions of foragers, the editors turn to their languages, mainly focusing on their relationship to and contacts with languages of foodproducers. The bibliography of this introductory paper is worthwhile on its own, providing any neophyte in the topic with an excellent starting point for independent discoveries.

The paper by Ellen Dröfn Gunnarsdóttir \& Mark Stoneking, "Genetic landscape of present-day hunter-gatherer groups", is an overview of genetic research on the difference between foragers and food-producers. As has been already mentioned, it is quite outdated, though a reader can learn that (a) groups of foragers generally exhibit lower genetic diversity in their mitochondrial DNA (mtDNA) than their agricultural neighbors, and (b) differences between foragers and foodproducers are greater for Y-chromosomes than for mtDNA. The former is explained by the numerical drop in forager populations conditioned by the expansion of agriculturalists, but also increased migration rates within the food-producers, while the latter is conditioned by higher migration rates for females since most human populations practice patrilocality. However, these observations are mainly based on African populations since only those were well researched 10-15 years ago.

Balthasar Bickel \& Johanna Nichols in "Linguistic typology and 
hunter-gatherer languages" study a hypothesis of a possible systematic linguistic differentiation between languages of foragers and those of food producers. After an introduction discussing the importance that this correlation, if discovered, would have for linguistic typology, they check more than two hundred phonetic, phonological, morphological, morphosyntactic, and syntactic variables represented in the AUTOTYP and WALS databases. With careful statistical analysis, they conclude that the languages of the two types of societies definitely belong to "the same grammatical ilk" (p. 72), and so the hypothesis is not supported by the current data on the world's languages. Since the main claim of the paper is negative, it is quite short, but its importance for the volume, and thus the field, should not be underestimated. Even though this is rather an open secret for typologists, the value of checking the linguistic equality of hunter-gatherers' languages is high for representatives of other disciplines. This could be particularly true for anthropology where the divide between the two types of societies has long been much more important than in linguistics.

The essence of Cecil H. Brown's paper "Ethnobiology and the hunter-gatherer/food producer divide" is a study of the difference in botanic terms between foragers and food producers, postulating for the latter a tendency to have binomial terms. The suggested explanation for the difference is more attention to plants from the part of cultivators as opposed to foragers, but it has no further grounding except for the difference discussed in the paper and for a reference to Berlin (1992). However promising, this study is limited to terms for the oak and to languages of the United States only (excluding Alaska). This makes it an interesting start for ethnobiological research into the topic of the volume, but it is clearly insufficient for making wider generalizations.

The papers by Güldemann, Blevins, and Epps turned out to be my favorites of the whole volume, serving as perfect examples of studies where historical linguistics sheds light on the human history of the respective areas. All three are brilliantly written: fully accessible to linguists unfamiliar with these languages, they seem not to be compromised for specialists either, providing accurate reconstructions, grammatical in the case of Güldemann and mainly lexical in the case of Blevins and Epps. These papers provide exemplary embodiments of the ways in which historical linguistics can inform models of hunter-gatherer prehistory. Last but not least, they show by their own 
examples that an argument from historical linguistics can be formulated in such a way that it is easy to read without previous knowledge of the history of this particular family - something not so often encountered within the subdiscipline of historical linguistics, including the long-established field of Uralic comparative linguistics.

Tom Güldemann in his paper "Changing profile when encroaching on forager territory: Toward the history of the Khoe-Kwadi family in Southern Africa" suggests a new history of South African languages. Modern Khoe-Kwadi languages are shown to be "a geographically marginalized remnant reflex of an earlier population spread supplanted by a later population spread" (p. 134), in the latter case by Bantu speakers. The earlier spread involved pastoralists speaking languages of the Khoe-Kwadi meeting indigenous foragers whose languages were related to the modern southernmost Kx'a and Tuu families (Khoe-Kwadi, Kx'a and Tuu together were earlier described as "Khoisan"). This spread coincided in time with, and most probably was conditioned by, the precipitation peak in summer rainfall 3,000-2,000 BP. When most of the area turned into desert once again, the pastoralists reverted to the foraging economy of the original population, thus today confusing researchers who have long held foraging to be the original state of the Khoe-Kwadi speakers. The main merit of this paper is the independent analysis of purely linguistic and non-linguistic (archaeological, genetic and cultural) data, where scenarios arrived at separately are compatible with each other, making thus a strong argument for the historical reconstruction.

The paper by Juliette Blevins "Linguistic clues to Andamanese prehistory: Understanding the north-south divide" uncovers the linguistic and cultural history of the Andaman Islands in the Indian Ocean. These islands are inhabited by "Negritos", "a descriptive term for dark-skinned frizzy-haired people of insular and mainland Southeast Asia, usually of short stature" (p. 200-201) who are thought to represent populations predating the influx of Austronesian and Austroasiatic speakers to the area. The inhabitants of the northern part of the island speak Great Andamanese languages and those of the southern part speak Ongan languages. Despite the genetic and cultural unity of the inhabitants of the Andaman Islands, the two linguistic families are not related to each other, with the former being Austronesian and the latter being Austroasiatic, as Blevins suggests in her paper. The attribution of Great 
Andamanese to Austronesian was shown by her in a previous paper, while the relatedness of Ongan to Austroasiatic is demonstrated for the first time in the current paper of the volume. These linguistic reconstructions hint either at distinct migrations to the two parts of the Andaman Islands, or to an ancient population split combined with extensive contacts with various parts of the mainland.

The paper by Patience Epps, "Language and subsistence patterns in the Amazonian Vaupés", is relatively short. Devoted to the Nadahup family, modern forest foragers of Amazonia, it studies the main elements of their horticultural and non-horticultural plant vocabularies, as well as those relating to cultivars. While the common wild-growing plant terminology is reconstructible for all four Nadahup languages, words for cultivars are of more recent origin, though attested in a genealogically defined subgroup of the family. Among the latter, many words are of Tukanoan and Arawakan origin, speakers of which are the Nadahups' agriculturalist neighbors. This discovery by means of classical comparativelinguistics methods allows for a relative dating of the introduction of exchange practices with the agriculturalists and of the beginning of limited horticulturalism among the Nadahup speakers. An earlier published study of the Nadahup numeral system, also summarized in the paper, supports the same scenario.

Graziano Savà \& Mauro Tosco's paper "Hunters and gatherers in East Africa and the case of Ongota (Southwest Ethiopia)" contributes to the debate on the possible historical ways in which huntergatherer communities developed, in particular in East Africa. It puts an earlier linguistic study by one of the authors into a larger, mainly ethnographic, context. The paper deals with Ongota, a small hunter-gatherer community in Southwest Ethiopia surrounded by food producers speaking Cushitic and Omotic languages (both Afro-Asiatic). Linguistically, the moribund Ongota language is very different from any of its neighbors largely due to its poor and isolating morphology. While the authors cannot show that a scenario of a separate language family spoken once by several hunter-gatherer communities is impossible, they insist that the current evidence is too weak to postulate this. Based on this and the ethnographic evidence connecting the Ongotas to a northern Omotic neighbor, they suggest the following cyclical development: first, a group of Omotic-speaking foodproducers became marginalized 
and shifted to foraging; while migrating to their current location, they experienced influences from other languages leading to a morphological profile unusual for the area; finally, today an assimilation to neighboring East Cushitic pastoralists is complete (the language is remembered only by the elders, there are no cultural distinctions, except for the lack of cattle by the Ongota). In their discussion of the Ongota case, Savà and Tosco are quite critical of other African cases where small hunter-gatherer communities with non-related languages have been claimed to represent an earlier, significantly more numerous, population. They focus on the weakness of the existing argument that can hold only if huntergatherers are thought to always precede food producers in a given location and no "devolution" of foodproducers into hunter-gatherers is possible. If this view is not taken for granted, all these cases can equally well be analyzed as such reversals.

The paper by Jørgen Rischel, "Hunter-gatherers in South and Southeast Asia: The Mlabri", starts with a concise but very meaningful overview of all hunter-gatherer groups of South and Southeast Asia with their linguistic affiliation. The author then concentrates on the linguistic history of one particular group, Mlabri, which has been shown by an earlier genetic study to represent a recently (500-800 years old) isolated forager group surrounded by food-producers, with their language showing both MonKhmer (more) and Sino-Tibetan features (less). Based on myths and detailed linguistic analysis, Rischel suggests that the Mlabri reverted to gathering from food-production with an aim "to preserve, or even re-establish, the ethnic identity and integrity of the group" (p. 152). Their language shows traces of the encounters that this small isolated group had in the past.

Niclas Burenhult in his paper "Foraging and the history of languages in the Malay Peninsula" uncovers the complicated human and linguistic history of the Malay peninsula and forms it into a clear, easyto-read narrative. A part of the Malay population are hunter-gatherers belonging to the "Negrito" genetic profile and speaking North Aslian Languages (Aslian < Austroasiatic); they are known as the Semang ethnographic unity (Burenhult provides a table of all Semang ethnolinguistic groups with detailed comments on their languages, locations, and current sociolinguistic situations; the data may seem peripheral to the bird's-eye view presented in the paper, but are clearly invaluable for those interested in this particular area). While two 
opposing hypotheses about the origin of the Semang have been earlier formulated, the author shows that the truth lies in between, and the Semang should be viewed "as neither isolated relics, nor recent 'by-products', but as a successful blend of old and new" (p. 190). To reach this conclusion, he sums up the analysis of lexical divergence and convergence within the Aslian languages (published earlier in a co-authored paper) and compares it to the published results of recent genetic studies; confronting the two allows him to arrive at a new level of understanding of language spreads on the peninsula. Last but not least, he adds an original sociolinguistic perspective to his analysis, suggesting that the types of linguistic interaction observed by the Semang are determined by their mobile lifestyle and "patterns of their group disintegration and regrouping [...] in response to changing subsistence conditions" (p. 187). High levels of individual variation and fuzziness of language boundaries are for Burenhult logical linguistic consequences of these social patterns. Personally, I was struck by this unexpected parallel to the recent past of the Northern Samoyedic groups (see Khanina (2021) for a sociolinguistic analysis of the former), with this parallel showcasing how promising cross-linguistic comparison can be in the case of the sociolinguistics of hunter-gatherer communities.

The paper "Historical linguistics and Philippine hunter-gatherers" by Lawrence A. Reid is devoted to languages of Philippines foragers, who, with one exception, have been described as a "Negrito" population (see an explanation of the term above). The main focus of the paper is on historical patterns of interaction between Philippine farmers and foragers, all of whom speak Austronesian languages today. Given that phenotypically foragers are different from the rest of Austronesian speakers, a shift - or rather many shifts - by the original Philippines population to the languages of the agricultural newcomers can be assumed. What remains to be determined is the particular scenario of historical relationships and their human and linguistic outcomes, and they are discussed in the paper with references to six case studies. Reid suggests that the close contacts between incoming farmers and the local population started soon after the arrival of the farmers, and the latter were clearly socially dominating in these interactions. Eventual conflicts and other social reasons led to regular breaks in contacts and thus to linguistic diversification, supported by the Negritos' eagerness to maintain separate 
linguistic identities. Original and very informative in its essence, this paper deals with evidence rather freely, and also risks losing its potential readership because of its less than superlative writing style. Without attention to the needs of linguists and anthropologists unfamiliar with languages of the Philippines (no introduction, no genealogical information for languages, insufficient maps, etc.), the author stands a chance of making his message accessible only to specialists in the area or very patient readers ready to invest their time in a certain amount of decryption.

In her paper "Hunter-gatherers of Borneo and their languages", Antonia Soriente presents an expert overview of forager languages of Borneo island. Unfortunate confusion and ambiguity of exonyms of the local nomadic groups (who usually do not use any autonyms) make it a difficult enterprise even for specialists to track their respective histories. Luckily, Soriente has devised a way to present the groups in quite a reader-friendly manner, with a combination of prose, informative tables, and maps. The organization of information on the genealogical subgrouping of their languages (all North Borneo Malayo-Polynesian < Austronesian) is less optimal, though this is indeed a complicated matter substantially, with many of the affiliations being yet uncertain and some of them elucidated directly in the given paper. The vastly underdescribed state of the general linguistic situation of Borneo is exemplified by an illuminative case study of a particular language/dialect, Penan Benalui, spoken by just 450 nomadic huntergatherers. Most of the case study is devoted to a comparison of Penan Benalui to some other neighboring languages, all ultimately related to it, with the aim of finding its particular place among the subbranches of the North Sarawakan languages, and simultaneously to refine the number and the status of these subbranches themselves. The detailed and clearly valuable comparative description of the phonology, grammar, and lexicon of Penan Benalui is not always easy to follow for a non-specialist, e.g. only by the end of the paper could I figure out what the main logical genealogical alternatives considered in the paper actually were. With the main topic of the volume in mind, Soriente pays particular attention to knowledge systems encoded by the Penan Benalui lexicon and how it differs from the lexicons of its sedentary neighbors. Finally, she concludes her paper with a hope that future molecular anthropology studies will contribute to the discussion of the complicated past and present 
relationship between various linguistic groups of Borneo island.

Malcolm Ross's paper "The linguistic situation in Near Oceania before agriculture" gives a broad overview of the history and linguistic situation of Near Oceania from its settlement by the first humans ca. 21,000 BP up to the arrival of Austronesian-speaking agriculturalists from the Asian mainland ca. 3,300 BP. He includes mainland New Guinea and Northwest Island Melanesia (= the Bismarcks, Bouganville, and the Solomon Islands) into his survey, basically delimiting himself by the territory where the so-called "Papuan" languages are spoken today (not a genealogical unity but a cover label for any non-Austronesian language of the area). The correlation between subsistence and languages in this part of the world is quite strong, with the languages of the biggest Papuan family, Trans-New-Guinea, being spoken by farmers and all the other Papuan languages, belonging to no less than 23 distinct families, being spoken by sedentary foragers living from "wild-food production" (i.e. reliance on wild sago-plants with occasional planting and minimal tending, e.g. by clearing underbrush). As can be expected, the Trans-New-Guinea farmers occupy most of the territory, with sagodependent communities scattered around the coastal areas. Ross refers to changes in the biogeography of the past to explain the persistence of non-farmers in these particular areas, and thus claims the non-TransNew-Guinea languages to be relics of the former linguistic diversity of Near Oceania. Interestingly, all languages of New Guinea could be genealogically connected, but since the time depth of their dispersal lies beyond the reach of the method of comparative linguistics, this continues to be only a hypothesis.

Mark Donohue's paper "Language, locality and lifestyle in New Guinea" starts with a short overview of diversity ranges in $\mathrm{New}$ Guinea's language communities in terms of geography and lifestyle. It then proceeds to an analysis of two case studies from North-Central New Guinea and one from the Western Highlands, in all of which the focus is on contrasting features of a language spoken by foragers and a language or languages spoken by its food-producing neighbors. These cases include both the neighborhood of related languages, as well as of unrelated ones. While the idea of the author could have been to identify some common linguistic features that would recurrently differentiate languages of foragers from those of food-producers, he concludes with a simpler claim that there is always at least one feature 
by which a hunter-gatherer population's language differs from the languages of its neighbors. This generalization is indeed supported by the data Donohue presents in this paper, but it seems to be true basically for all neighboring language pairs of the world. This is in line with the conclusions of the typological paper of this volume, that by Bickel \& Nichols, stating that there are no regular differences between languages based on the subsistence mode of their speakers.

Peter Sutton's paper “Small language survival and large language expansion on a hunter-gatherer continent" is an impressive original study that would be hardly realizable without the author's exceptional level of expertise in the languages and peoples of Australia. First, Sutton provides a thorough reconstruction of language group sizes in Australia at the time of colonization (1788), proving with robust numbers the abundance of very small languages unattested anywhere beyond Australia (note also the seven-page Appendix to the paper with estate/language data for ca. 150 cases of Australian linguistic varieties, in itself definitely valuable). He then proposes a theoretical explanation for the observed group sizes and their dynamics, where a state of equilibrium, ideologically based on the famous Australian link between land and linguistic identity, is diversified by episodes of punctuation conditioned rather by external factors. Finally, he tentatively puts forward a hypothesis that the Pama-Nyungan expansion was triggered by a catastrophic population collapse outside the modern non-Pama-Nyungan zone at ca. 3,800 years BP, caused itself by epidemics brought by Asian seafarers via northern Australia. Last but not least, Sutton contributes to the main topic of the volume by suggesting that Australian evidence argues that "languages are not automatically endangered by their smallness" (p. 370), and that small hunter-gatherer languages can thrive in their multitude for millennia when not disturbed by spreads of agriculturalists.

Mark Harvey's paper "Language and population shift in pre-colonial Australia: Non-Pama-Nyungan languages" discusses mainly nonPama-Nyungan languages of Australia with a particular focus on regional and supraregional changes in the geographical locations of languages. These are meticulously reconstructed for three groups of languages based on (a) lexical and grammatical borrowings dated for protolanguage levels, (b) significant differences in age between families deduced from the level of reconstructability of each particular 
protolanguage, and (c) internal structure and overall transparency of place names for the current territory of the languages involved. To these non-Pama-Nyungan spreads, Harvey adds some observations on the directions of a supraregional spread for Pama-Nyungan languages, based in turn on the geographic differences in their internal diversity and in the space they occupy. Both types of spreads are framed by the author as examples of a possibility which turns out to be not so rare after all: the spreading of language families without rapid increases in population based on the adoption of new modes of production. So, while quite specific in its descriptive part, this paper suggests rather broad methodological conclusions, and also sets an illustrative example of implications that can be drawn from a thoughtful combination of a historical-linguistics approach and attention to geographies of languages.

Patrick McConvell's paper "The spread of Pama-Nyungan in Australia" is a mix of methodological reflections on the typology of language spreads, with a focus on foragers' spreads, and of analysis of specific semantic changes in Pama-Nyungan. The paper looks rather like a summary of previous work, as most of its claims are not supported by direct evidence, but readers are referred to various published works, many of them by the author himself. For example, McConvell insists on the validity of Pama-Nyungan as a linguistic family, arguing with Dixon and presumably other skeptics, but an outsider to Australian linguistics like myself would rather be interested in more substance of the debate than in a plain advertisement of the proposed view. The analysis of semantic changes includes case studies from the kinship domain, as well as from terms for directions, flora, and fauna. They are meant to support the main methodological idea that semantic changes in these domains occur in a language (family) during its spread to uninhabited or sparsely inhabited territory, while borrowings indicate a language (family) spreading to densely populated territory with an active presence of other languages. This is an instance of McConvell's more general typology of "upward (or skirting)" vs. "downward (or encroaching)" forager spreads (cf. Evans \& McConvell 1998; McConvell 2001, 2010), discussed in detail in another paper of the volume, that by Hill. Finally, it could be mentioned that McConvell's paper is not very friendly to linguists unfamiliar with these languages or at least with Australian geography (e.g. of 10 case studies, only one is 
accompanied by a map), and the descriptions of particular cases are not always detailed and precise, resembling more illustrations than evidence-based argumentation.

The only part of the volume that deals with languages somewhat familiar to me is "Northeastern Eurasia". It includes only two papers: one by Vajda, "Typological accommodation in Central Siberia", devoted to the grammatical evolution of the Yeniseian family of Central Siberia, and the other one by Anderson \& Harrison, "Huntergatherers in South Siberia", devoted to language-encoded cultural data from the two South Siberian Turkic languages Tofa and Todzhu.

Edward J. Vajda demonstrates how Yeniseian languages, originally prefixing, accommodated through centuries to the areal suffixing profile set by neighboring Samoyedic, Tungusic, and Turkic languages. This has been achieved by (a) innovating a new root position at the leftmost edge of the phonological verb, and (b) developing nominal relational morphemes into a case-like system. The scenario is well presented and overall convincing, even though the sociolinguistic argument is a bit underdeveloped. Besides, it is not always clear from the prose whether the author has skipped an exposition of some evidence due to the lack of space or there is no solid evidence available to him yet. Examples are the cases of borrowings in the domains of spiritual culture and family (p. 474), the Kets' unilateral bilingualism in the past (p. 475), and the prefixing nature of the Proto-Yeniseian verb (p. 488).

Gregory D. S. Anderson \& K. David Harrison take it as a starting point that the foraging lifeway leaves clear traces in a language, and their paper is devoted to enumeration of such traces for Tofa and Todzhu (with significantly more data from Tofa), foragers speaking Turkic languages. They assume that these traces can primarily be found in features atypical for Turkic languages, which are well known for the pastoralism of their speakers. Crucial for their argument is historical evidence: two travelers of the 18th century described the Tofas as a group with a Samoyedic language, and one of them even recorded some Tofa words, undoubtedly Samoyedic. A possible Yeniseian substrate has also been suggested in the literature for Tofa and Todzhu. The paper itself does not focus on linguistic attribution of the substrate, but rather on its connectedness to the hunter-gatherer lifestyle. The connection is quite convincing and supported by parallels from other hunter-gatherer languages (with a reader directed 
to references for more information). However, from a Uralic, or even Samoyedic perspective, one cannot help noticing that no Tofa or Todzhu feature discussed by Anderson \& Harrison could be attributed specifically to Samoyedic, at least without a separate dedicated study. In other words, the Samoyedic character of the substrate is taken for granted, which is not precisely accurate given its importance for the central claim of the paper: it is from their previous language(s) that these people brought the unTurkic features corresponding to their forager lifestyle. The paper would have gained from a more open treatment of the potential sources for the non-Turkic features, including a possible description, here missing, of the ethnolinguistic history of the area and of the current neighbors of Tofa and Todzhu.

Willem J. de Reuse's paper "Primitivism in hunter and gatherer languages: The case of Eskimo words for snow" revises the discussion in the recent literature of the Eskimo terms for 'snow'. While it has recently been successfully shown that there are two, or three at most, general terms for snow, and not only several dozen specific terms, this paper brings forward an anthropological consequence of this linguistic analysis. De Reuse not only focuses the reader's attention on the Eskimo ability for logical reasoning and generalizations evidenced by the lexicons of their languages, but also deconstructs the unfortunate myth from the linguistic point of view. The main part of the paper breaks down the details of Eskimo grammar which obscure the parallels with English, as an example of a foodproducer language. Once the parallels are restored, the Eskimo system no longer looks so unusual, though the level of elaboration in the domains of snow and ice vocabulary is clearly higher given its importance for survival in the Arctic region.

The paper by Richard A. Rhodes, "Language shift in the Subarctic and Central Plains", explores the last 500 years of the history of Algonquianspeaking hunter-gatherer groups of the Great Lakes area in North America, with a particular focus on Cree and Ojibwe-Potawatomi. It has been designed with two methodological aims in mind, and so can be of particular interest not only for those curious about the linguistic history of North America, but much more broadly. On the one hand, a careful description of language spreads in a recent period with written historical documentation can, by the author's intention, positively contribute to building a typology of spreads, invaluable for reconstruction of prehistoric spreads. On the other hand, 
which is more immediately relatable to most readers, Rhodes discusses actual Algonquian spreads of the Great Lakes as examples of logically possible types of language spreads, sometimes drawing parallels from more well-documented European ethnolinguistic history. The paper is very dense in the data discussed, though Rhodes' style of presentation is not always friendly to those unfamiliar with languages and geography of the area. For example, as many as six maps for different historic periods are provided, but the language names featured on them are inconsistent, presumably reflecting various traditions, and many of the maps lack geographic details referred to in the text (e.g. names of lakes or of modern states); the description of vowel reduction (p. 568) could have gained a lot from a table, a chart, or a map that would help a non-specialist to follow the author's logic, etc.

Jane H. Hill in her paper "UtoAztecan hunter-gatherers" checks the hypothesis formulated by Evans and McConvell (1998) and McConvell (2001) on the general features of hunter-gatherers' spreads against the data of the Northern Uto-Aztecan languages spoken in the USA. The hypothesis predicts that "downstream" (later also called "encroaching" by McConvell, see above) spreads of languages into densely inhabited territories will find a linguistic reflection in more significant substratum phenomena as compared to cases of "upstream" (or "skirting") spreads into mostly empty territories. Hill discusses this hypothesis in detail and also summarizes some other ideas expressed on sociogeographical factors in hunter-gatherer language variation and spreads. I find this methodological section particularly appealing, not only for a good collection of relevant features, but also for its accessible writing style. Returning to the Northern Uto-Aztecan languages, its Takic and Numic subgroups are taken as perfect examples of the two kinds of spreads, "downstream" and "upstream", since the former migrated to Southern California, famous for its linguistic diversity, while the latter spread into the relatively unpopulated Great Basin; the two spreads largely coincide in their dating. Surprisingly, Hill discovers that neither lexical diversity, measured as the percentage of nonUto-Aztecan words in a wordlist, nor typological diversity, calculated with the help of the WALS inventory of features (Haspelmath et al. 2005), indicate any difference in the amount of substratum within the languages of the two subgroups. As discussed at the end of the paper, this result indicates that the reality is more complicated than the 
model: effects of particular events in some historical periods can be blurred by subsequent events, substratum effects are hard to measure in a uniform way through various languages, and there might be more sociolinguistic details to take into account, e.g. the linguistic effects of outside females marrying into a community, that may run parallel to any type of spread.

Alejandra Vidal \& José Braunstein in their paper, somewhat misleadingly entitled "The Southern Plains and the continental tip", trace the general human and linguistic history of the last 4000 years for the Gran Chaco area in South America, which comprises ca. 50 social units speaking 18 different languages from 6 distinct genealogical groups. Due to the ecology of the region, it was impossible to carry out agricultural activities here, so that not only were the original Gran Chaco population foragers, but groups migrating to the area also reverted to foraging, at least partly. The authors describe the consecutive stages in the peopling of the area and the linguistic consequences of these events. They suggest specific patterns of interand intraethnic communications that are responsible for unexpectedly high rates of linguistic divergence (for related languages) and of linguistic convergence (for all languages, including the unrelated ones) observed today.

\section{Conclusion}

The overwhelming majority of the papers of the volume dealt with languages I knew very little about, but while reading them I could not help returning in my mind to the history of Samoyedic, my personal area of interest. That was because different scenarios attested in the history of those languages repeatedly suggested to me new questions I could apply to my own data. This is indeed one of the basic aims of linguistic typology: to supply descriptive linguists with an array of possibilities attested in the world's languages, so that each feature of every particular language could be described in reference to that pool of options. This way, more thorough descriptions can be achieved, which in their turn will successfully feed the next round of typological, and ultimately theoretical, thinking. The same logic applies here: for advancing the field of language evolution and history, in the broadest sense of these terms, it is crucial to treat the history of each family in the context of other known histories and spreads. To make such an analysis possible, every historical linguist should make use of comparable terminology and be fully explicit in one's reasoning, 
setting aside the cryptic conversation of specialists only talking to each other that has been far too common in the comparative-historical field, including Uralistics.

Finishing this enthusiastic review, I find it appropriate to express my acknowledgement to the editors of the volume for putting all these papers together. Every contribution being solid on its own, jointly they picture an impressively detailed portrait of hunter-gatherers' languages and bring historical-typological linguistics to a new level. By far, this could be one of the first attempts to build a typology of language spreads bottom-up, without promotion of any specific theory, but giving equal voice to a diversity of languages, types of evidence, and ways of reasoning.

\section{Olesya Khanina}

\section{References}

Bellwood, Peter. 2013. First migrants: Ancient migration in global perspective. Chichester: Wiley-Blackwell.

Berlin, Brent. 1992. Ethnobiological classification: Principles of categorization of plants and animals in traditional societies. Princeton, NJ: Princeton University Press.

Evans, Nicholas \& McConvell, Patrick. 1998. The enigma of Pama-Nyungan expansion in Australia. In Blench, Roger \& Spriggs, Matthew (eds.), Archaeology and language II, 174-192. London: Routledge.
Haspelmath, Martin \& Dryer, Matthew S. \& Gil, David \& Comrie, Bernard (eds.). 2005. The World atlas of linguistic structures. Oxford: Oxford University Press.

Khanina, Olesya. 2021. Languages and ideologies at the Lower Yenisei (Siberia): Reconstructing past multilingualism. In Dobrushina, Nina \& Khanina, Olesya \& Pakendorf, Brigitte (eds.), special issue "Typology of small-scale multilingualism" of International Journal of Bilingualism 25(4). 1059-1080.

Lee, Richard B. \& Daly, Richard (eds.). 1999. Cambridge encyclopedia of hunters and gatherers. Cambridge: Cambridge University Press.

McConvell, Patrick. 2001. Language shift and language spread among hunter-gatherers. In Panter-Brick, Catherine \& Layton, Robert H. \& Rowley-Conwy, Peter (eds.), Hunter-gatherers: An interdisciplinary perspective, 143-169. Cambridge: Cambridge University Press.

McConvell, Patrick. 2010. The archaeolinguistics of migration. In Lucassen, Jan \& Lucassen, Leo \& Manning, Patrick (eds.), Migration history in world history: Multidisciplinary approaches, 155-190. Leiden: Brill.

Panter-Brick, Catherine \& Layton, Robert H. \& Rowley-Conwy, Peter. 2001. Lines of enquiry. In Panter-Brick, Catherine \& Layton, Robert H. \& Rowley-Conwy, Peter (eds.), Hunter-gatherers: An interdisciplinary perspective, 1-11. Cambridge: Cambridge University Press. 